Foot Structure and Accent in Seneca

\author{
Alissa Melinger
}

International Journal of American Linguistics, Vol. 68, No. 3. (Jul., 2002), pp. 287-315.

Stable URL:

http://links.jstor.org/sici?sici=0020-7071\%28200207\%2968\%3A3\%3C287\%3AFSAAIS\%3E2.0.CO\%3B2-M

International Journal of American Linguistics is currently published by The University of Chicago Press.

Your use of the JSTOR archive indicates your acceptance of JSTOR's Terms and Conditions of Use, available at

http://www.jstor.org/about/terms.html. JSTOR's Terms and Conditions of Use provides, in part, that unless you have obtained prior permission, you may not download an entire issue of a journal or multiple copies of articles, and you may use content in the JSTOR archive only for your personal, non-commercial use.

Please contact the publisher regarding any further use of this work. Publisher contact information may be obtained at http://www.jstor.org/journals/ucpress.html.

Each copy of any part of a JSTOR transmission must contain the same copyright notice that appears on the screen or printed page of such transmission.

The JSTOR Archive is a trusted digital repository providing for long-term preservation and access to leading academic journals and scholarly literature from around the world. The Archive is supported by libraries, scholarly societies, publishers, and foundations. It is an initiative of JSTOR, a not-for-profit organization with a mission to help the scholarly community take advantage of advances in technology. For more information regarding JSTOR, please contact support@ jstor.org. 


\title{
FOOT STRUCTURE AND ACCENT IN SENECA ${ }^{1}$
}

\author{
Alissa Melinger
}

\author{
Max Planck Institute for Psycholinguistics
}

1. Introduction. In Seneca, the position of accent is determined by the position and structure of the accented syllable and also by the position and structure of the following (post-tonic) syllable. Adding to the complexity of this already unusual situation is the fact that these two syllables relevant for accent placement are traditionally parsed into two different metrical feet. There has been considerable discussion among phonologists on how best to capture the accent pattern formally within various metrical frameworks (Halle and Vergnaud 1987, Hayes 1995, Kager 1993, Prince 1983, and Stowell 1979). The most widely accepted analysis of the system, namely, the analysis proposed by Prince (1983), faces new challenges due to recent elaborations on the description of the accent pattern. This paper provides a comprehensive account of the Seneca accent system that addresses the fact that both the tonic and post-tonic syllables play a role in determining accent assignment. Additionally, the present analysis is compatible with the phonological processes of vowel lengthening which interact with accent assignment and with more recent descriptions of the phenomena.

Accent in Seneca is restricted to even-numbered syllables. ${ }^{2}$ Prior analyses have assumed that this restriction reflects an iambic foot structure. However, it is commonly known that a surface weak/strong alternation is not equivalent to iambicity. Thus, this paper makes one basic claim. I argue that the Seneca accent system can be explained more simply and naturally if the foot structure is reanalyzed as trochaic. Much of the complexity of

\footnotetext{
${ }^{1}$ Earlier versions of this paper were written at the University at Buffalo, State University of New York. My sincerest thanks go to Karin Michelson for her patience, support, and linguistic insights. I would also like to thank Wallace Chafe for taking an interest in this paper and for providing me with extremely useful comments and criticism. I also want to thank an anonymous reviewer for helping me create a clearer, more precise final manuscript. Additional thanks go to Wendy Baldwin, Eve Ng, J. P. Koenig, and Hanni Woodbury. All errors and omissions are my own.

${ }^{2}$ As will be seen below, this claim holds only for the underlying vowel count, not for the surface pattern. Seneca has several phonological processes which result in surface representations with accented odd-numbered syllables. For example, intervocalic $h$ deletion can produce long accented vowels in odd-numbered syllables, such as in há:'dathęs 'he's thirsty', from the reconstructed *hahâ'dathęhs.
}

[IJAL, vol. 68 , no. 3 , July 2002 , pp. 287-315]

(C) 2002 by The University of Chicago. All rights reserved. 0020-7071/2002/6803-0002\$10.00 
the accent assignment system stems from a single property of the iambic analysis, namely, that the pair of syllables which interact to predict where accent is assigned is not within the same iambic foot. Adopting a trochaic foot structure rectifies this problem. The trochaic analysis proposed in this paper accounts for the pattern of Seneca accent and lengthening that prior analyses have dealt with and, at the same time, addresses new data which provide new insights into the nature of the Seneca accent patterns.

Section 2 introduces the facts about accent in Seneca, including the syllabification constraints which are pertinent to accent assignment and a description of the prosodic phenomena with which accent interacts. It also outlines some of the basic theoretical assumptions of iambic analyses. Section 3 begins with a discussion of the problems of prior analyses, which universally assume an iambic foot structure. A new trochaic analysis which avoids the problems faced by iambic analyses is outlined in the metrical framework of Hayes (1995). Following the analysis of accent assignment, I present some typological arguments in support of the trochaic proposal. At the end of 3, I review the prior analyses of Seneca accent and show how they fall short of capturing all the facts of the system. The paper concludes with a review of the findings.

2. The data. All the data used in this study are taken from Chafe's (1967) Seneca Morphology and Dictionary, except where otherwise explicitly noted. The orthographic system, however, has been brought up-to-date with more current usage by linguists working on Seneca and by the native community in the classroom (see Chafe 1996 for a guide to the orthography). Additionally, I include proposed metrical structure and syllabic boundaries in examples when needed for expository purposes. The data cited in the dictionary are citation forms and the accent rule discussed is word-level accent, which is distinct from phrasal intonation that extends beyond the domain of the word.

2.1. The realization of accent. The phonetic correlate of accent in Seneca is high pitch or $\mathrm{f}_{0}$. Chafe describes, and spectrographic analyses reveal, that accented syllables have a higher fundamental frequency than nonaccented syllables in a word (Chafe $1967 ; 1998)$. Although syllables contrast in their relative pitch, Seneca is not a TONE language because tone is not a paradigmatic property of Seneca. The tonal specifications for a given syllable or word pattern generally are not lexically specified; rather, they are metrically determined. Furthermore, since Seneca does not use other phonetic cues such as intensity or duration to distinguish accented syllables from unaccented syllables, Seneca is a nonstress accent language in the terminology of Beckman (1986). Because Seneca relies on a single phonetic 
cue for distinguishing accented and unaccented syllables, there has been some debate about whether the high pitch realized on accented syllables should be viewed as a phonologically represented High tone on a tonal tier or as the phonetic realization of the metrically determined accent system. Arguments for each alternative are discussed in the concluding remarks. I argue that the existence of multiple accents in a single word makes a tonal analysis unlikely, due to its need for crossed association lines.

2.2. Accent assignment. Historically, Proto-Northern-Iroquoian (hereafter PNI) accented the penultimate syllable. Additionally, if the penult was open, it was lengthened. This pattern, with slight variations, is still found in two of the five PNI languages, namely, Mohawk and Oneida. These languages are analyzed as consisting of a single trochee aligned with the right edge of the word (Michelson 1988). The initial portion of the word remains unfooted. The three other PNI languages (Cayuga, Onondaga, and Seneca) have integrated an odd/even syllable count into the original PNI accentual system with complex results. Of all the PNI languages, Seneca is the least faithful to the original PNI accentual system.

While accent assignment in PNI was sensitive only to a syllable's position in a word (penult or not), accent assignment in Seneca is sensitive both to a syllable's position and structure and to the structure of adjacent syllables. Specifically, the contrast between open and closed syllables is crucial for accent assignment. For purposes of accent assignment, obstruent + obstruent, obstruent + laryngeal, as well as $s n$ and $s w$ sequences are heterosyllabic. ${ }^{3}$ In addition, a single intervocalic laryngeal consonant ( $h$ or ') is parsed into coda position rather than onset position, closing the preceding syllable. Other consonant clusters, such as obstruent + sonorant or sonorant + sonorant clusters, are tautosyllabic. The examples in (1), which include syllable boundaries, illustrate these syllabification constraints.

(1a) a.gę.ni.yás.da.yé

(1b) go.dék.ho:.ni:h

(1c) o’.dís.wa.de.nyę:.doh

(1d) a.ge.ga.yé'.oh
'I have it on me'

'She's eating'

'You (pl.) waded'

'I'm willing' obstruent + obstruent sequence obstruent + laryngeal sequence [s.w] sequence, but not [n.y] in penult single laryngeal consonant

\footnotetext{
${ }^{3}$ Different phonological phenomena in Seneca require different syllabifications of the segments. Since the constraints on syllable structure in Seneca are not straightforward, only the syllabification constraints directly relevant for accent assignment are discussed in this paper (see Melinger 1997 for a full discussion of the syllabification constraints in Seneca).
} 

(1e) o'.gy $Q:$ dy $Q: h$
'It's snowing'
[dy] tautosyllabic
(1f) a.ge.gwe.nyo:h
'I'm able to'
[gw] and [ny]
tautosyllabic

$(1 a)-(1 c)$ illustrate some of the heterosyllabic consonant sequences. In ( $1 a)$, a sequence of two oral obstruents is syllabified into two different syllables. In $(1 b)$, a sequence of an oral obstruent followed by a laryngeal consonant is heterosyllabic, as is the [sw] sequence in (1c). Additionally, $(1 d)$ demonstrates that a single laryngeal consonant is syllabified into the coda of the preceding syllable rather than the onset of the following syllable. The resulting closed syllables in these words are eligible for accent. In contrast, the consonant sequences in (1e) and (1f) are tautosyllabic. As a result, these words do not have a closed syllable eligible for accent.

Given the syllabification constraints shown above, an informal statement for Seneca accent assignment is formulated in (2):

(2) Counting from the beginning of the word, accent every nonfinal even-numbered syllable that is either closed or immediately followed by a closed syllable. Do not accent penults that have undergone Even Penultimate Lengthening (see 2.3). If there is no closed nonperipheral syllable, the word has no accent (adapted from Chafe 1996).

Since the count to determine odd and evenness begins at the left edge of the word, Seneca has generally been interpreted as requiring the construction of right-headed or iambic feet from left to right (e.g., Stowell 1979, Kager 1993, and Prince 1983). The examples in (3)-(6), which include iambic feet and syllable boundaries, capture some of the possible accent patterns. The words in (3) provide several examples in which an even-numbered closed syllable is accented.

(3a) (a.ge)(ga.yé') $q h$

(3b) (a.ga)(wa.sé')(he'.qh)

(3c) (a.gę)(ni.yás)(da.yę)

(3d) (sha.nóh)(sa.dih)

(3e) (o'.dís)(wa.de)(nye.doh)

(3f) (de.yóh)(soh.gwa:)ge:h
'I'm willing'

'I've gotten a new one'

'I have it on me'

'on the other side of his house'

'You (pl.) waded'

'two colors'

$(3 a)-(3 f)$ are all examples in which the accented syllable is closed. Furthermore, in each of the words, the accented syllable is the only (evennumbered) closed, nonperipheral syllable in the word. In $(3 b)-(3 d)$, the antepenult is accented. $(3 b)$ illustrates that only even-numbered syllables can receive accent in Seneca; the odd-numbered penult in this word is also closed, but it cannot carry accent, nor can the closed final syllables in (3a)$(3 d)$. The words in $(3 e)$ and $(3 f)$ illustrate that accent can occur early in the 
word, not only on or adjacent to the penult. In this respect, Seneca, unlike the other Northern Iroquoian languages, has almost completely separated itself from the original PNI accent system. Only (3a) has the same position for accent as the reconstructed PNI form.

As stated in (2) above, even-numbered syllables need not be closed to receive accent. If an open even-numbered syllable is followed by a closed odd-numbered syllable, then the even-numbered syllable can still receive accent, as illustrated in:
(4a) (de.o)(no.da)(dye.nó)(wo'.se:h)
(4b) (sa.ę)(no.dá)(nygh.so:')
(4c) (khe.nó)(węh.dọh)
(4d) (ha.yá)(do'.gwas)
(4e) (go.nó) (Qh.gwa')
(4f) (da.yé) (goh.so)(da.dye')
(4g) (e.wó)(geh.sa:)dé

'They're helping each other' 'They put the things back in' 'I didn't believe them' 'He's digging a hole' 'I love you' 'Faces keep appearing' 'I'm going to ride on its back'

In each of the examples in (4), the even-numbered accented syllable is open while the subsequent odd-numbered syllable is closed. As with the examples in (3), those in (4) demonstrate that accent can occur on any even nonfinal syllable in a word. If the penult is odd and closed, accent is assigned to the antepenult, as in $(4 a)-(4 e)$. However, unlike in PNI and other Northern Iroquoian languages, the crucial requirement is not that accent occur on the penult or antepenult but rather that it fall on an even syllable that fulfills the requirements regarding its proximity to a closed syllable. Thus, in (4f), accent falls on the second syllable and not on the antepenultimate syllable, since both the antepenult and the penult are open. Likewise, in $(4 \mathrm{~g})$, the second syllable, which is open, is accented, instead of the closed odd-numbered antepenult.

Now that the basic pattern of accent distribution has been established, two further aspects of Seneca accent merit discussion: (1) Seneca words can have more than one accent and (2) not all words have an accent.

It is a relatively recent observation that Seneca words can have more than a single accented syllable but this observation is crucial to the present analysis. The entries in Chafe's (1967) dictionary mark only one word-level accent per word; however, more recent work has found that every accentable syllable-namely, every even-numbered syllable that is either closed or followed by a closed syllable-is produced with equally high pitch (Chafe 1996; 1998). These additional high pitches are present in elicitation forms as well as in several discourse styles. ${ }^{4}$

\footnotetext{
${ }^{4}$ Chafe eschews the term "secondary accent" when referring to these additional accents since the data suggest that there is no hierarchical relationship between the rightmost accent and the other accents in the word; they are all of equally high pitch (Chafe 1996).
} 
The examples in (5) show some words with more than one accented syllable.

(5a) (de.wá)(gę.ní)(goh.q.')

(5b) (de.yọ́k)(hi.yấ)(do.wéh)(da.nih)

(5c) $($ de.wá) $(g e \cdot . n y o)(d a . g e ́)) g h$

(5d) (o'.khé)(yas.he)(da.wi')ho.'

(5e) $($ de'.ja $)($ go.yá')(dos.gá) $a h$
'I long to be somewhere else'

'They deliberated for us'

'I'm busy'

'I gave them numbers'

'She's pregnant' (lit., 'it's not her body anymore)'

(5f) (de.yQ)(gwa.déh)(at.hé)(dah.goh) 'that which gives us light'

(5g) (wa.o)(wo.di)(ya'.dó')ne:k

'They removed them'

In $(5 a)$ and $(5 b)$, every nonfinal even-numbered syllable is accented since each is either closed or followed by a closed syllable. However, it is not necessary for accents to occur at regular rhythmic intervals. In $(5 c)$ and $(5 d)$, accents occur on the second and sixth syllables but not on the fourth syllables since they do not meet the criteria. Likewise, in $(5 e)-(5 g)$, the fourth and sixth syllables are accented but not the second. These examples also illustrate that the additional accents are assigned under exactly the same conditions as the rightmost accent; they occur only on even-numbered syllables which are either closed or followed by a closed syllable.

An additional feature of the Seneca accent system is that words can occur without any accented syllable if the word has no medial closed syllable. The existence of words without any high pitched syllable has been reported repeatedly by Chafe $(1967 ; 1977 ; 1996)$. These words are produced with a relatively even low tone throughout the word. Some examples of words with no accented syllable are:

(6a) (ak.de:)nyo:h

(6b) (sha.go)(ge:.das)

(6c) (de.wa)(ga.de:)no:d

(6d) (de.ga) (de.nye) $($ o.de')

(6e) (ha.da:)khe's *(ha.dá:k)(he's)
'I've changed it'

'He hates her'

'I'm wishing it would happen'

'I'll put a necktie on'

'He's running about'

The words in (6) have no accented syllable because they lack a medial closed syllable. These words also demonstrate that peripheral syllables can neither bear nor condition accent. Despite the fact that many of these words have odd-numbered final closed syllables, these syllables cannot condition accent onto an open even penult. Furthermore, the accent system in Seneca prefers to have no word-level accent rather than assign accent to an oddnumbered syllable such as the closed initial syllable in $(6 a)$. (6e) highlights an additional complication of the system. According to the syllabification constraints discussed in (1) above, the penult of this word should be closed. It does not receive accent because of an interaction between accent assign- 
ment and the phenomenon of Even Penultimate Lengthening (henceforth EPL). Penults which have been lengthened by this process cannot be accented (EPL is discussed in 2.3). Thus, lengthening by EPL results in a large set of accentless words.

The fact that Seneca would rather produce accentless words than violate any of its accent assignment constraints violates a well-established metrical constraint of culminativity which states that "each word or phrase has a single strongest syllable bearing the main stress" (Liberman and Prince 1977:262, quoted in Hayes 1995:24). This is one of the arguments used for a partially tonal analysis of Seneca accent, as will be seen in $\mathbf{3}$ below.

2.3. Even penultimate lengthening. Even penults are often lengthened in Seneca, and this lengthening phenomenon interacts with the distribution of accent. EPL applies only to even-numbered penults, counting from the beginning of the word in the same manner as for accent. An informal description follows:

(7) Even penults are lengthened unless the vowel is immediately followed by a laryngeal.

The examples in (8) illustrate this phenomenon.

(8) Penult lengthened:

(8a) o'gyo:dyo:h

'It's snowing'

Compare:

(8b) dewágahsę:thwęh 'I'm crying' osdęodyq: $h$ dewáhsęthwas

'It's raining'

(8c) hada:khe's

'He's running

eyédakhe' 'fleas' (lit., 'it cries') about'

'She'll be running'

Penult not lengthened:

(8d) agegayéégh

'I'm willing'

The even penults in the left column of $(8 a)-(8 c)$ have all undergone lengthening. Compare these words to morphologically related words in the right column, in which the same vowels are short when in odd-numbered syllables. $(8 d)$ shows that even penults that are followed by a laryngeal consonant are not lengthened.

(8c) also shows that penults lengthened by EPL can no longer be assigned accent despite being followed by heterosyllabic consonant sequences. ${ }^{5}$ In fact, EPL and accent are in complementary distribution. If a

\footnotetext{
${ }^{5}$ Traditionally, the fact that lengthened penults cannot be accented has been attributed to a process of resyllabification. Specifically, lengthening of the penult blocks the syllabification of consonants into the coda (Michelson 1988 and Melinger 1997). Thus, clusters which otherwise would close a syllable for accent are resyllabified into the onset of the ultima. Syllable boundaries in subsequent examples represent this fact.
} 
penult is lengthened by EPL, earlier syllables can still be accented, but not the penult, as shown in:

(9a) (o'.gé)(ga.ha:)tho'

(9b) (da.gá) (de'.ha:)sdo:'

(9c) (ha: wíh)(sa'.ha:)sde'

(9d) (ye’.á)(šyoh.ga:)tha'

(9e) (da:)(yo.gwá)(da'.swe:)kho: $k^{6}$
'I turned it inside out'

'I exerted myself'

'He has strong muscles'

'basket medicine'

'We should keep our ears closed'

For each example in (9), the penult is even and followed by a nonlaryngeal consonant; thus, it is lengthened but not accented, since a penult lengthened by EPL cannot bear accent. If there are no other closed syllables present in the word, then the word will have no accent, as in:
(10a) (ha.da:)khe's
'He's running about'
(10b) (de.wa:)kdo'
'I've put it around it'
(10c) (o'.tha:)snye:'
'He took care of it'
(10d) (ga.da)(ni.de::)stha'
'I plead forgiveness'
(10e) $($ de'.ga $)($ do.gwe:)tha'
'I'm not doing very well'

The environments in which EPL is blocked are often opaque in surface representations due to the deletion of $h$ intervocalically, before sonorants, and before sequences of two obstruents. For example, according to the description of EPL in (7), the penult in (11a) should lengthen, not be accented. EPL does not apply, however, because in the underlying representation the penult is followed by an $h$ which deletes when followed by two obstruents. The presence of the $h$ can be seen in the related word in $(11 b)$.
(11a) (sga.dát)(he.wá)tha'
*(sga.dát)(he.wa:)tha'
s-g-adat-hewaht-ha'
REPET-1SA-RECIP-punish-ASP
'I repent'
(11b) (o'khé)(:wáh)(da:nø:')
$o^{\prime}$-khe-hewaht-no-'
INDIC-1/F-punish-DISTRIB-ASP
'I punished several of them'

In addition to the interaction between EPL and accent assignment described above, EPL also complicates foot construction in Seneca. As noted by Prince (1983), the distinction EPL makes between even and odd penults

\footnotetext{
${ }^{6}$ The long vowel in the first syllable of this example is derived from underlying /ara/ or $/ a h a /$. When the intervocalic consonant is deleted, the two identical vowels merge into a single long vowel on the surface. However, these long vowels are still treated as two separate syllables for foot construction (Chafe 1959; 1996 and Michelson 1988).
} 


\author{
Iambic foot structure \\ [w $\mathrm{w}]\left[\begin{array}{ll}\mathrm{w} & \mathrm{s}\end{array}\right]\left[\begin{array}{ll}\mathrm{w} & \mathrm{s}\end{array}\right]\left[\begin{array}{ll}\mathrm{w} & \mathrm{s}\end{array}\right]\left[\begin{array}{ll}\mathrm{w} & \mathrm{s}\end{array}\right]$ \\ $1\left(\begin{array}{lll}2 & 3\end{array}\right)(4 \quad 5)(6 \quad 7)(8 \quad 9) 10$ \\ Units for accent assignment
}

FIG. 1

demands that binary feet iterate throughout the word. If foot construction did not iterate throughout the word, then there would be no way to make the even/odd distinction required by EPL. Since EPL targets syllables to the right of the accented syllable, foot construction cannot stop at the head of the word as some analyses propose (Stowell 1979 and Halle and Vergnaud 1987).

To summarize, these examples clearly demonstrate that the Seneca accent system prefers to have no accent rather than violate any of the conditions on accent assignment. Accent is not assigned to odd-numbered syllables, final syllables, or penults which have been lengthened by EPL. But accent can be assigned to an open even syllable, if it is followed by a closed syllable.

3. A new approach to Seneca accent. Since Seneca restricts accent to even-numbered syllables, linguists have analyzed the metrical system as iambic (e.g., Kager 1993 and Prince 1983). However, iambicity has greatly complicated the formulation of rules or constraints for accent assignment. The complication arises when the even accented syllable is open and the subsequent odd syllable is closed. Under an iambic parse of a word, these two syllables are in two different metrical feet. Since the foot is the logical and natural unit to which accent assignment constraints refer, it is difficult for theories to account for the nonisomorphism between the foot and the unit relevant for accent assignment. Following the Faithfulness Condition (Halle and Vergnaud 1987), one expects a conditioning syllable to act within a common foot, not across feet. The separation of the relevant syllables forces violations of the Faithfulness Condition and thus causes problems for metrical analyses. The crossing of the foot boundary is illustrated in figure 1 .

In figure 1, iambic feet are constructed over the syllables, represented as [w s]. Underneath the syllables is the syllable count, starting at the beginning of the word. The syllable count illustrates that each pair of even and odd syllables relevant for accent assignment crosses the iambic foot boundary. The greatest challenge facing an iambic analysis of Seneca accent assignment is to find a way for these two syllables to interact. One possibility is to remove the boundary between the two syllables so that they can influence each other for accent. Another possibility is to make accent assignment sensitive to the properties of the syllables yet blind to the foot boundary separating them. 
Additionally, an iambic analysis must prevent the odd-numbered syllables from conditioning accent within the common iambic foot. As dictated by the Faithfulness Condition, accent should shift rightward to the syllable in the strong position within the same foot, as in (12a). This would be more natural under an iambic parse and also more consistent with the PNI preference for accent to occur at the right edge of a word. If Seneca is an iambic language, then assigning accent leftward across a foot boundary, as in the attested example in $(12 b)$, is quite an unexpected pattern.

$(12 a) *($ daye $)($ gohsó $)($ dadye')

(12b) (dayé)(gehso)(dadye') 'Faces keep appearing'

There have been several approaches to solving this problem but none can capture all of the accent and accent-related phenomena currently under discussion. Proposals that rely purely on the metrical structure fail to account for the facts of EPL (Stowell 1979 and Halle and Vergnaud 1987). Proposals that assume a hybrid analysis, combining tonal and metrical structure, fail to account for multiple accents (Prince 1983). The trochaic analysis proposed below groups the two syllables relevant for accent assignment into a single foot, simplifying the process of accent assignment. Furthermore, an account of both EPL and multiple accents develops naturally out of the analysis for single accent assignment.

3.1. Trochaic analysis of Seneca accent assignment. The present analysis of Seneca accent takes the complication of separated syllables discussed above as a starting point and asks whether it is possible to create a metrical parse of Seneca words that combines the even-numbered and subsequent odd-numbered syllables into the same foot. One way to obtain this desired result is to assume initial extrametricality and a trochaic foot structure. This metrical structure produces a greatly simplified analysis of Seneca accent assignment. Furthermore, additional support for analyzing Seneca as a trochaic language comes from an investigation of the typological characteristics of trochaic and iambic languages, as is discussed in 3.2. Additionally, some evidence for initial extrametricality can be found in an examination of other Iroquoian languages.

The examples in (13) show the proposed trochaic foot structure. Initial syllables remain unparsed. Subsequent syllables are parsed into trochaic $(\mathrm{s} \mathrm{w})$ feet, from left-to-right. In (13a), the fourth syllable is closed and in strong position, thus it receives accent. The benefit of a trochaic foot structure is seen in $(13 b)$. Here, the closed odd-numbered syllable (\#3) that conditions accent is in the same foot as the even-numbered open syllable (\#2) that is assigned accent. 
$(13 a) \sigma[\mathrm{s} \mathrm{w}][\mathrm{s} \quad \mathrm{w}]$

1 (2 3) (4 5)

a gega yế'gh

'I'm willing'

$(13 b) \sigma[\mathrm{s} w][\mathrm{s} \mathrm{w}] \sigma$

$1(2)$ (4) 5) 6

dayégohsodadye'

'Faces keep appearing'

Accent assignment, be it on an open or closed even-numbered syllable, can now be assigned in the same manner in a typologically very natural way.

Before a formal analysis of Seneca accent is presented, one drawback of the trochaic analysis must be addressed: By default, even-numbered prominence is associated with iambicity. A trochaic analysis of Seneca must devise a way to parse even-numbered syllables into the strong position of the foot. I achieve this using initial extrametricality, which enables the two relevant syllables for accent assignment to be parsed into a common foot while maintaining even-numbered prominence.

While this is not the most common usage for extrametricality, it is not the first proposal of the sort (see Hale and White Eagle 1980 and Heiberg 1995 for evidence and arguments for initial extrametricality in Winnebago). Furthermore, there is some indication from other Iroquoian languages that the initial syllable holds a special, possibly extraprosodic, status. For example, Cayuga has a process of Laryngeal Metathesis which applies to nonfinal odd-numbered syllables, as in (14). However, [h] metathesis only applies to initial syllables that begin with an oral obstruent, as in (14a) but not (14b) (examples and description from Foster 1982). In these examples, $H$ represents a metathesized $[\mathrm{h}]$, resulting in a "whispered quality" on the vowel, and $h$ represents an unmetathesized [h].

(14a) koHsrõ:nih 'She has made it'

(14b) ẽhẽnató:wat 'They will hunt'

*ẽHẽnató:wat

The initial syllable also holds a special status in Onondaga. Onondaga exhibits a process of pretonic lengthening in which underlyingly short vowels in even pretonic syllables are lengthened if the vowel in the following stressed syllable is also long or closed by a laryngeal consonant (Chafe 1970, Woodbury 1981, and Michelson 1988). ${ }^{7}$ In determining whether a

\footnotetext{
${ }^{7}$ Michelson interprets this lengthening process as a resolution of a clash conflict. This analysis is further supported by Dyck's (1997) analysis of Cayuga accent assignment as being strongly motivated by clash avoidance.
} 
syllable is even or odd, word-initial clusters that begin with an oral obstruent cause the initial syllable to count as the second syllable. In other words, initial syllables with oral obstruent onset clusters are counted as two syllables. Examples from Michelson (1988) are given here:

(15a) twakati:yé:ta' 'I'm pulling it'

(15b) ętkatiyé:ta' 'I'll pull it'

Although the historical antecedent for the special treatments of initial syllables is unclear, it does provide converging evidence that Iroquoian languages assign a special status to initial syllables, making it more plausible that Seneca had historical reasons for developing initial extrametricality. ${ }^{8}$

While the present analysis posits an extrametrical initial syllable, it does not also require an extrametrical final syllable to prevent final syllable accent, although prior analyses did. This is important since it is highly unusual to have two extrametrical elements within a word. Final extrametricality is not necessary under a trochaic analysis provided that degenerate feet are disallowed, a fairly common cross-linguistic pattern (Prince 1980, McCarthy and Prince 1986, Kager 1989, and Hayes 1995). If degenerate feet are banned, then even-numbered final syllables remain unparsed. Extrametricality was also required in iambic analyses to prevent closed odd-numbered final syllables from conditioning accent on an open even-numbered penult. However, since open even penults are lengthened by EPL, they are not eligible for accent assignment, irrespective of the structure of the final syllable. Thus, as long as EPL is ordered before accent (or ranked above the accentrelated constraints in an OT framework), which it must be to block accent, final extrametricality is not necessary. These observations are represented in the derivation in (16) where $\mathrm{C}$ represents a final closed syllable.

\footnotetext{
${ }^{8}$ One argument against initial extrametricality is the fact that Seneca has a minimal word restriction. Specifically, Seneca content words must have at least two syllables. When a content word consists morphologically of only a single syllable, a prothetic $i$ is inserted at the beginning of the word, *dye:t $\rightarrow$ idye:t 'she's standing there' (Chafe 1996). Since minimal word restrictions are generally thought to be motivated by the need for every word to be at least one foot (allowing it to also be a prosodic word [McCarthy and Prince 1986]), the insertion of an additional syllable argues against initial extrametricality and the trochaic foot structure. However, the fact that these minimal words never bear accent suggests that the two-syllable string is NOT parsed into a foot at all. In fact, Chafe argues that the prothetic $i$ in Seneca is related to the PNI "need for a penultimate syllable that would accept the Proto-Northern Iroquoian penultimate accent" (1996:557), a pattern which no longer holds for Seneca. Thus, it is possible that the minimal word restriction in Seneca is a holdover from the PNI accent system and not related to the synchronic accent system.
} 
(16) $/ \sigma \sigma \sigma \sigma \sigma \sigma \mathrm{C} /$

$\langle\sigma\rangle(\sigma \sigma)(\sigma \sigma)(\sigma \mathrm{C}) \quad$ Initial Extramet + Parse Trochees

$\langle\sigma\rangle(\sigma \sigma)(\sigma \sigma)(\sigma: \mathrm{C}) \quad$ EPL

$\langle\sigma\rangle(\sigma \sigma)(\sigma \sigma)(\sigma:$ C) BLOCKED ACCENT Assignment

If initial syllables in Seneca are extrametrical and trochaic feet are constructed from left-to-right, then the accentable syllables can be identified by taking advantage of the foot as a unit within which accent assignment rules or constraints apply. Accent assignment can now simply be described as "accent the head of feet which contain a closed syllable." This idea is simple - the head of a foot can only be accented if the foot meets one main criterion, namely, that it contain a closed syllable. This criterion could be formalized in several ways. I propose one such formalization below within Hayes's (1995) framework.

The trochaic analysis proceeds as follows: Accent is assigned to each closed syllable in a word, but when accent is assigned to a syllable in weak position, the mark on the metrical grid at the word (W) level shifts to the head of the foot, so as not to violate the Continuous Column Constraint (henceforth CCC) which states that a grid mark on level $n+1$ must dominate a grid mark on level $n$ (Prince 1983). I invoke the general rule Move $\alpha$ to repair CCC violations (Prince 1983). When both the weak and strong syllables are marked, the weak grid mark is simply deleted. As will be seen, this is somewhat similar to Prince's tonal analysis, except that the motivation for shifting the mark leftward is to stay within the same metrical constituent, respecting both the Faithfulness Condition and the CCC. In contrast, Prince's motivation is an ad hoc spreading rule which is not supported by related languages.

To formalize this analysis, the following steps are proposed:

Step 1: Mark the initial syllable as extrametrical.

Syllable Extrametricality $\sigma \rightarrow\langle\sigma\rangle / \#$

Step 2: Build quantity insensitive left-headed binary feet from left-to-right. Foot Construction: Form syllabic trochees left-to-right

(i) degenerate feet banned

(ii) strong local parsing is invoked

(iii) footing is nonpersistent

Step 3: Build unbounded feet at the word level headed by closed syllables.

Step 4: Move $\alpha$ to respect the Continuous Columns Constraint and the Faithfulness Condition.

These four steps are illustrated in (17). Closed syllables are underlined. Accented syllables are in boldface. The example on the left illustrates an 
accented closed syllable and the example on the right illustrates an accented open syllable followed by a closed syllable.

(17) Steps 1 and 2: Initial extrametricality + L-to-R trochees, no degenerate feet

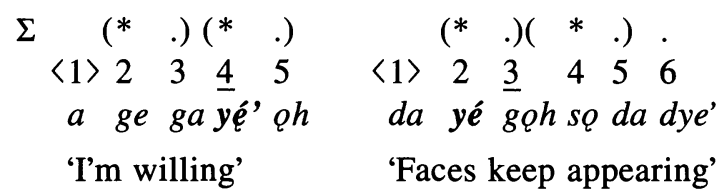

Step 3: Assign a Foot-level grid mark to each closed syllable

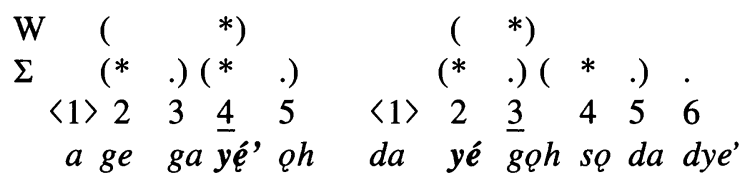

Step 4: Respect Continuous Column Constraint and Faithfulness Condition with Move $\alpha$

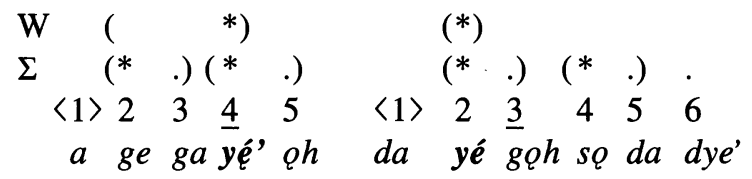

In (17), we see how trochaic feet allow the proper relationship between closed odd syllables and accented even syllables to be expressed. Once the odd-numbered syllable which conditions accent and the preceding evennumbered syllable are in the same foot, natural and typologically common constraints can be invoked for accent assignment. When an even-numbered syllable is closed, it receives a word-level grid mark that respects the CCC; thus, it receives accent. When an odd-numbered syllable is closed, the grid mark assigned at the word level violates the CCC since there is no grid mark at the foot level. The general rule Move $\alpha$ combined with the restriction against crossing foot boundaries, the Faithfulness Condition, conspires to shift the grid mark onto the preceding even-numbered syllable.

As discussed above, Seneca words can also have multiple accents or no accent. The derivations in (18) show how the current analysis accounts for these two situations.

(18) Steps 1 and 2: Initial extrametricality + L-to-R trochees, no degenerate feet

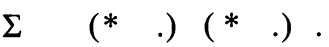
$\langle 1\rangle 2 \quad 3 \quad 4 \quad 5 \quad 6$
de ga de nye o de'
'I'll put a necktie on'

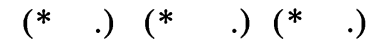
de wá ge' nyo da gế' $Q h$
'I'm busy'
〈1〉 $2 \quad \begin{array}{lllll}3 & 4 & 5 & 6 & 7\end{array}$ 
Step 3: Assign a Foot-level grid mark to each closed syllable

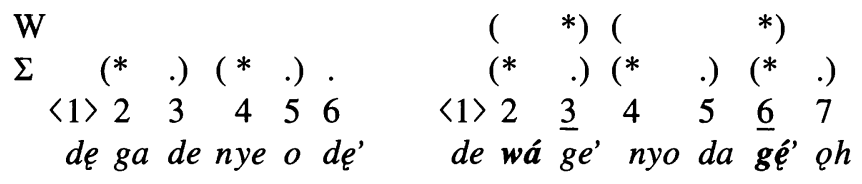

Step 4: Respect Continuous Column Constraint and Faithfulness Condition with Move $\alpha$

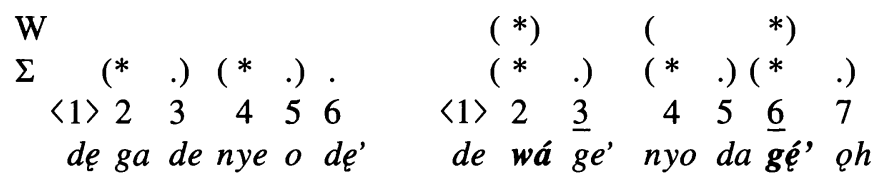

The violation of culminativity in these examples is represented by constraint-governed foot construction at the word level rather than a traditional End Rule (Prince 1983). Constraint-governed foot construction allows a word to have multiple feet or no feet at the word level. As the example in the left column of (18) illustrates, when there are no medial closed syllables, no word-level grid marks can be assigned; thus, the word is produced without an accented syllable. In contrast, when a word has multiple medial closed syllables, such as the example in the right column, multiple unbounded feet are constructed at the word level. Grid marks that violate the CCC shift in exactly the same way for multiple accents as they do for a single accent.

One additional situation must still be illustrated. When a single foot consists of two closed syllables, then two grid marks will be assigned at the word level. In this situation, the grid mark which violates the CCC cannot shift leftward. Since it has nowhere to move, it is simply deleted, as shown in (19).

(19) Steps 1 and 2: Initial extrametricality + L-to-R trochees, no degenerate feet

$$
\begin{aligned}
& \Sigma \quad\left(\begin{array}{llllll}
* & . & (* & & * &
\end{array}\right) . \\
& \text { 〈1〉 } 2 \quad 3 \quad \underline{4} \quad \underline{5} \quad 6 \\
& \text { a ga wa sé, he' } g h
\end{aligned}
$$

'I've gotten a new one'

Step 3: Assign a Foot-level grid mark to each closed syllable

$$
\begin{array}{llllll}
\mathrm{W} & ( & \multicolumn{3}{c}{\left.{ }^{*}\right)} & (*) \\
\Sigma & (* & .) & (* & .) & \\
\langle 1\rangle & 2 & 3 & 4 & 5 \\
a & \text { ga } & \text { wa } & \text { sé, } & \frac{5}{h e}, & \text { gh }
\end{array}
$$




\section{Step 4: Respect Continuous Column Constraint and Faithfulness Condition with Move $\alpha$}

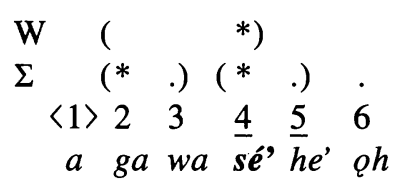

The present analysis accounts for all of the various characteristics of Seneca accent. It correctly assigns accent to even-numbered syllables that are either closed themselves or in the same foot as a closed syllable. Degenerate, nonbinary feet are disallowed under this analysis, a claim that is supported by most typological accounts of metrical systems. As a result, even-numbered final syllables which are ineligible for accent do not pose a problem since they remain unfooted. Additionally, this analysis can correctly account for words that have no accent or multiple accents. As shown below, prior analyses could not easily accommodate multiple word accents.

Finally, since binary feet are constructed throughout the whole word, this analysis allows evenness to be distinguished for post-tonic penults. As discussed in 3.3, this was the primary shortfall of prior analyses which attempted to account for Seneca accent using only metrical structure. Furthermore, lengthened even penults are not accented because lengthening triggers resyllabification (see $\mathrm{nn} .2$ and 4), resulting in long open penults which are not eligible for accent.

There is one phonological phenomenon which may pose a problem for the current trochaic analysis, namely, the distribution of accents on vowel + vowel sequences. In Seneca, when an unaccented vowel immediately precedes an accented vowel, the accent spreads over the entire sequence, resulting in a sequence of two accented vowels (*oríhwa' $\rightarrow$ óíwa' 'cause'). However, when an accented vowel is immediately followed by an unaccented vowel, the accent does not spread (ogáa' 'eye') (Chafe 1996). Assuming an iambic foot structure provides a parsimonious explanation for this asymmetrical pattern; accent spreads within foot boundaries but not across foot boundaries. Thus, the iambic parse of the VV sequence in which accent spreads is $\left(v v^{\prime}\right)(\sigma \sigma) \rightarrow\left(v^{\prime} v\right)(\sigma \sigma)$. The iambic parse of the VV sequence in which accent does not spread is $\left(\sigma v^{\prime}\right)(v \sigma) \rightarrow(\sigma v)(v \sigma)$. In contrast, the trochaic analysis cannot invoke the foot to explain this spreading process. It is also possible that the distribution of accent across VV sequences is motivated by a phonetic constraint against rising tones rather than a constraint against having a tone cross a foot boundary. Indeed, there are several phenomena which typically respect foot boundaries but which ignore them in Seneca. Syllable construction is such an example. 
In addition to the long vowels produced by EPL and compensatory lengthening (as discussed in $\mathbf{2 . 3}$ and 3.2.2, respectively), Seneca has a third type of long vowel derived from two identical vowels separated by an intervocalic $r$ or $h$ which has been subsequently lost (Chafe $1959 ; 1967)$. When a disyllabic long vowel is parsed into the strong branch of an iamb, it spreads over two feet, holding positions in both the strong branch of one foot and the weak branch of the other: *hodiriyó'de' > (hodi)(:yó')de' 'They're working'. The behavior of disyllabic long vowels is just one example of Seneca phonology ignoring foot boundaries (and vowels ignoring syllable boundaries). Thus, while I do not have a full account for why accent patterns the way it does in VV sequences, it is unlikely to be motivated by foot boundaries and may be due to a general phonetic constraint against rising tones rather than a phonological process of spreading within the foot boundary.

3.2. Additional evidence for the trochaic analysis. The present analysis of Seneca accent captures the full range of accent-related phenomena in this language. Analyzing Seneca as trochaic is beneficial because it creates symmetry between the unit within which accent assignment constraints refer and the metrical foot. However, a pattern of even syllable prominence is most naturally viewed as iambic. In order to posit trochees I had to also assume an extrametrical initial syllable, which is typologically rare and even disallowed by some (e.g., Hayes 1989 and 1995). While I have presented some evidence from related languages for a special status of initial syllables, the analysis would be more compelling if it were supported by additional evidence for trochaic feet. Additional evidence comes from a comparison of the typological characteristics of iambic and trochaic languages with the characteristics exhibited by Seneca.

Hayes (1995) discusses several characteristics of iambic languages. Three relevant characteristics are listed in $(20 a)-(20 c)$ and discussed in turn below.

(20a) Quantity sensitivity

(20b) Lengthening of strong branches

(20c) Long vowels should attract accent

3.2.1. Quantity sensitivity. Foot construction in languages can be either quantity sensitive, i.e., sensitive to a distinction between light (L) syllables and long, heavy (H) syllables, or insensitive, i.e., blind to the length or weight of a syllable. Iambs are argued to be universally quantity sensitive (Hayes 1995). Trochees, in contrast, can be either quantity sensitive or insensitive. Seneca, as an iambic language, is a clear counterexample to this generalization. In fact, Kager (1993), arguing against an asymmetric foot typology, cites Seneca as a language with syllabic iambs. 
As we have already seen, Seneca has long vowels that result from EPL. But, Seneca also has other sources of vowel length. For example, Seneca has a process of $h$ deletion before sonorant consonants, R. Vowels in these environments lengthen to compensate for the loss of the $h, * \mathrm{~V} h \mathrm{R}>\mathrm{V}: \mathrm{R}$ (Chafe 1967, Chafe and Foster 1981, Hayes 1989, Michelson 1988, and Mithun 1979). The lengthening of the vowel to compensate for the loss of $h$ suggests that $h$ bears a mora, contrary to the claim by Hayes (1995) that it is weightless. Since syllables with long, bimoraic vowels are universally heavy, they should always contribute to weight in a quantity-sensitive system (Hyman 1985).

An iambic language should exhibit traits of quantity sensitivity, i.e., foot construction should be sensitive to syllable weight. When an $\mathrm{H}$ (heavy) syllable is encountered as the second element in an iamb, it should be incorporated into the strong branch of the foot, since an iamb can consist of LH syllables. This is schematically depicted in (21).

Typologically natural

Iambic feet $(\mathrm{L} \mathrm{L})(\mathrm{L} \mathrm{H})(\mathrm{L} \mathrm{L})(\mathrm{L} \mathrm{L})$

Syllables $\quad \begin{array}{llllllll}1 & 2 & 3 & 4 & 5 & 6 & 7 & 8\end{array}$

However, iambs of the type (HL) are typologically disallowed; therefore, syllables with a long vowel at the left edge of an iamb should comprise an entire iamb, $(\mathrm{H})$. This, in turn, begins a new W/S alternation. As a result of offsetting the W/S alternation, the observed contrast between even- and odd-numbered syllables should also be offset. This is schematically depicted in (22).

Typologically natural

Iambic feet $(\mathrm{L} \mathrm{L})(\mathrm{H})(\mathrm{L} \mathrm{L})(\mathrm{L} \mathrm{L}) \mathrm{L}$

Syllables $\quad \begin{array}{llllllll}1 & 2 & 3 & 4 & 5 & 6 & 7 & 8\end{array}$

(22b) Typologically unnatural

Iambic feet $(\mathrm{L} \mathrm{L})(\mathrm{H} \mathrm{L})(\mathrm{L} \mathrm{L})(\mathrm{L} \mathrm{L})$

Syllables $\quad \begin{array}{llllllll}1 & 2 & 3 & 4 & 5 & 6 & 7 & 8\end{array}$

In (22), the third syllable is $\mathbf{H}$. Since it is the first syllable in a new foot, it completes the iamb. The next syllable, then, begins a new iamb. The even-numbered syllables following this heavy third syllable are now in the weak positions of subsequent iambs, not strong. Thus, even-numbered syllables that follow a heavy syllable should no longer be eligible for accent. The footing in (22a) incorrectly predicts which syllables can be assigned accent following an odd-numbered syllable with a long vowel. Instead, the footing in $(22 b)$ is the attested pattern in Seneca; the foot structure (HL) is maintained. This footing is the only pattern that can account for the placement of accent in words with odd-numbered long vowels, such as in (23a). 
In this example, the long vowel in the first syllable is derived by compensatory lengthening due to the loss of $h$ before sonorants. (23a) shows that syllables with long vowels derived via compensatory lengthening are treated as light by foot construction; ${ }^{9}$ they can occur in either branch of a foot (as $23 b$ shows) and they do not reset the construction of iambs for the word.
$(23 a)$
$\begin{array}{cc}\mathrm{f} & \mathrm{f} \\ / & /\end{array}$
ga:yá'ehda'
(not ga:ya'éhda') 'Eagle Dance Pole'

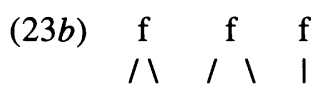
wadẹ:ni'd ókthá (from wadęhni'dóktha') 'the end of the month' $\begin{array}{lllll}1 & 2 & 3 & 4 & 5\end{array}$

Thus, while Seneca does have a weight contrast, foot construction is insensitive to it. This renders Seneca a very unusual iambic language. However, it is not an unusual trochaic language, as trochees are commonly quantity insensitive, i.e., they ignore length distinctions when constructing feet.

3.2.2. Lengthening of the vowels of strong branches. Additional differences between iambic and trochaic languages were based on experimental studies of the perception of alternating rhythm pairs. Woodrow (1909; 1911) found that long elements of alternating rhythm pairs (... - - - - - - . .) are perceived as the second element of the pair, i.e., final prominence. On the other hand, more intense elements of alternating rhythm pairs $(\ldots-=-=-=-=-\ldots)$ are perceived as the initial element of the pair, i.e., initial prominence. Hayes links this perceptual generalization to linguistic metrics in the Iambic/Trochaic Law, which states that strong branches of iambs are phonetically and perceptually distinguished by length, while strong branches of trochees are phonetically and perceptually distinguished by intensity (Hayes 1995:80).

In Seneca, however, accent is realized as high pitch, not as an increase in intensity or duration. Although Hayes makes no claims about how pitch should behave with respect to the perception of rhythm pairs, studies that included a rhythm pair which alternated in frequency found that these pairs are also perceived as initially strong (Bell 1977 and Handel 1974). In other words, intensity and frequency are both perceived as initial prominence. Furthermore, pitch and intensity are highly integrated acoustic properties;

\footnotetext{
${ }^{9}$ Recall that Seneca also has surface long vowels which are derived by the loss of $h$ and $r$ between two identical vowels. In these cases, the fact that the long vowel is derived from two separate vowels is respected by the foot structure; a long vowel can encompass an entire foot $(\mathrm{H})$ or it can be divided across feet $(\mathrm{x}(\mathrm{H}) \mathrm{x})$, violating the Faithfulness Condition.
} 
it is very difficult to increase a tone's pitch without the perception of increased amplitude as well. Likewise, when the intensity of a tone is lowered, it is often perceived as having a lower pitch. In contrast, pitch and length are not integrated acoustic properties. Thus, as relates to the Iambic/Trochaic Law and the relationship between rhythm group perception and metrical prominence, Seneca patterns more, acoustically and perceptually, with trochaic systems than with iambic systems.

3.2.3. Accented syllables should be lengthened. Since iambs are always sensitive to weight, syllables with long vowels should attract stress, especially when they are in strong position. Hayes (1995:222-26) makes this point when presenting his case for classifying Seneca as a quantitysensitive iambic language. Hayes argues that most long vowels in Seneca are derived from underlying VC, which patterns as light for purposes of foot construction. In contrast, he claims that the long even penults are derived "deeper in the phonology" and, therefore, attract stress. For Hayes, this supports the claim that Seneca iambs are truly quantity sensitive. However, this portrayal of the interaction between EPL and accent in Seneca is incorrect, as the data in $\mathbf{2 . 3}$ show. Hayes confuses the tonic lengthening phenomenon of Cayuga, an iambic language, with Seneca's Even Penultimate Lengthening. In Cayuga, odd-numbered open penults lengthen, while closed penults do not. If the penult is odd and long, it attracts accent. This is clearly a very different pattern from the one found in Seneca where EPL blocks accent from being assigned. The rule and example from Cayuga in (24) are taken from Hayes (1995:223).

(24) Tonic lengthening II (Cayuga):

$$
\begin{aligned}
& \mathrm{X} \\
& \mathrm{V} \rightarrow \mathrm{V}: /[\sigma]_{\text {word }} \\
& \text { ękàtatòkw'etónyye? } \rightarrow \text { [ękàtatòkw'etọ́:nyę?] }
\end{aligned}
$$

'I will make some people for myself'

(24) shows that when a penult is accented in Cayuga, that vowel is lengthened. ${ }^{10}$ This phenomenon contrasts with the facts of Seneca's EPL, as described in 2 above: lengthened penults in Seneca cannot be accented.

Interestingly, the Seneca data are actually more similar to the facts of Oneida, a trochaic language. In Oneida, when an open penult is accented, it undergoes lengthening. In an attempt to maintain even trochees, the lengthening causes the accent to shift rightward to the final syllable (Michelson

\footnotetext{
${ }^{10}$ Hayes's formulation of Cayuga Tonic Lengthening puts a slightly different spin on the process. His rule claims that accented penults are lengthened. Conversely, many Iroquoianists claim that open penults lengthen and therefore attract accent (Chafe 1977 and Dyck 1997). It is also possible that these long accented penults are retentions from the PNI pattern where both accent and length were present.
} 
1988). The process in Seneca is similar in that accent must shift off of the lengthened penult.

It has also been noted that stressed syllables do lengthen in trochaic systems; however, it has been argued that the phenomenon is restricted to monomoraic feet (Prince 1990). The penults which are lengthened by EPL necessarily form part of bisyllabic feet (regardless of whether an iambic or trochaic foot structure is assumed) and therefore are not expected to lengthen when stressed. Thus, the fact that Seneca eschews stressing a lengthened penult is consistent with typical trochaic characteristics.

There are several other characteristics that are typical of iambic languages, such as the preference to construct feet from left-to-right. However, the other criteria are not relevant to the current discussion since both iambs and trochees can freely construct feet from this direction and thus Seneca is compatible with both. Of the characteristics that Hayes proposes to strongly distinguish iambs from trochees, Seneca patterns as trochaic for all of them.

Clearly, the observation that Seneca does not exhibit characteristics typically associated with iambic languages is not enough to shatter an iambic analysis. In fact, the universality of these characteristics, and of the typological asymmetry in general, is controversial (see Kager 1993). However, it is interesting that Seneca has few of the characteristics usually associated with iambic languages but many of the characteristics associated with trochaic languages. Combine this fact with the observation that iambic analyses fail to account for the full range of data that are naturally accounted for by the trochaic analysis and a compelling argument arises.

Now that I have presented a trochaic analysis of Seneca and the typological characteristics that also support the reclassification of Seneca's foot type, I briefly present the prior iambic analysis. Each of the prior analyses deals only with the assignment of the rightmost accent in a word. However, I examine the ability of each of these analyses to incorporate an analysis of multiple accents as well. As will be shown, none of the prior analyses can both distinguish even- and odd-numbered penults and account for multiple accents in a word.

3.3. Prior analyses. Stowell's (1979) analysis of accent in Seneca posits two distinct foot structures: right-branching unbounded feet, $F$, and rightheaded (w s) bounded feet, f. In Stowell's analysis, the right-branching unbounded foot is constructed first, starting from the end of the word. It progresses leftward, incorporating as many syllables of the word as it can, until it encounters a branching rhyme (represented here in boldface). Since the right-branching structure of the foot cannot incorporate the left-branching structure of the rhyme, foot construction terminates. The remaining unfooted portion of the word is grouped into right-headed binary feet, starting 


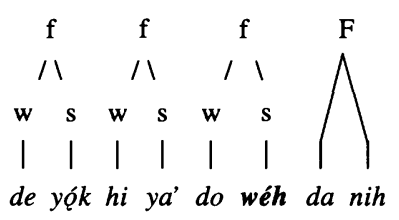

'They deliberated for us'

FIG. 2

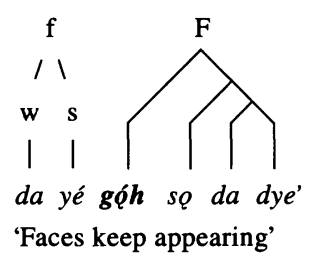

FIG. 3

from the beginning of the word. Accent is attributed to the head of the last binary foot. An example of this foot structure is provided in figure 2 . If the rightmost closed syllable is odd, it adjoins to the unbounded foot rather than into a degenerate foot, as in figure 3.

Stowell's analysis is quite ingenious in that it divides the word into two domains and assigns accent to the end of the first. However, a fundamental flaw of the analysis, identified by Prince (1983), is that the binary alternations must continue throughout the word in order to correctly distinguish even and odd penults for EPL. Specifically, Prince argues that since an open penult must lie within the domain of Stowell's final unbounded foot, "oddness" in Stowell's model cannot be ascertained in post-tonic syllables, as can be seen in figure 3 .

In figure 3, the odd-numbered penult is not followed by a laryngeal; EPL would apply if it were even-numbered. However, since the binary feet do not iterate throughout the entire word, there is no way to determine whether this syllable is even or odd. This same fatal flaw is present in Halle and Vergnaud's (1987) metrical analysis.

Halle and Vergnaud (1987) develop a framework that combines an alternating grid with constituents, or feet. In figure 4, the column on the left is an abstract example of a word with an odd-numbered closed syllable, and the column on the right is an abstract example of a word with an evennumbered closed syllable. Closed syllables are represented with a caret below the syllable number.

Halle and Vergnaud begin their derivation with the construction of leftheaded unbounded feet which are headed by a closed syllable, starting at the end of the word. This first step is shown in $(a)$ of figure 4 . Next, the 
(a) Build left-headed unbounded feet headed by closed syllables.

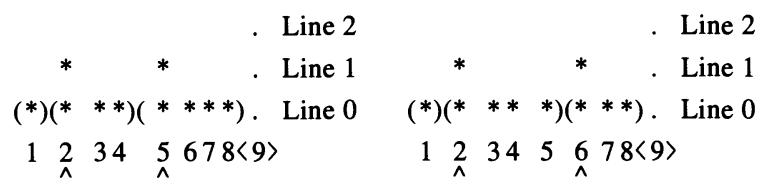

(b) Identify the rightmost head as word head.

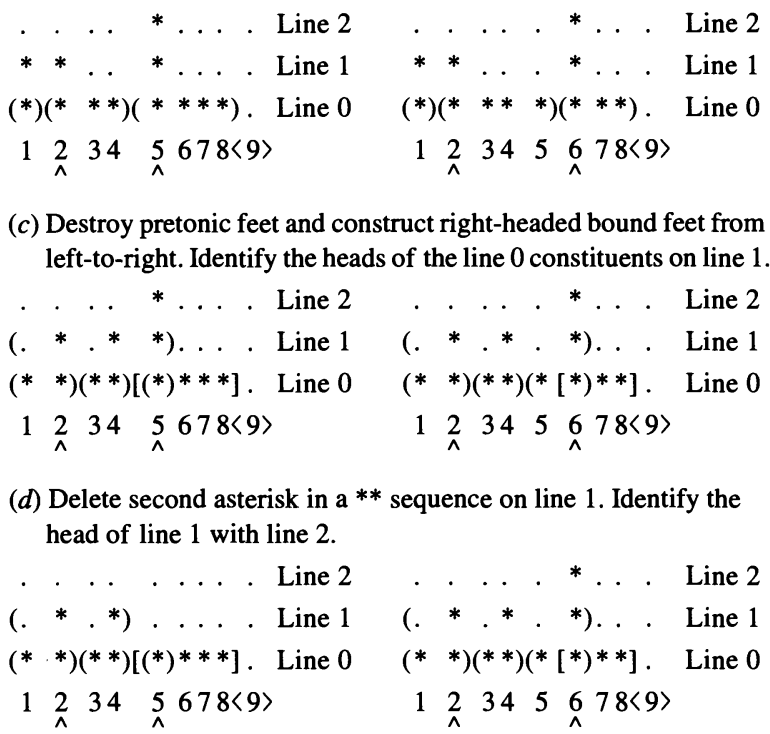

FIG. 4

head of the rightmost foot is identified as the head of the word, as in $(b)$. All pre-tonic feet are then destroyed and right-headed bounded feet are constructed from left-to-right, stopping at the word head, as in $(c)$. When the word head is an even syllable, accent can be assigned at this point. However, when the word head is odd, there is a clash violation on grid line 1 which must be resolved. So the second peak is deleted and the preceding syllable becomes the new word head $(d)$. They thus account for accent shifting leftward.

Clearly, this analysis is quite complex. It requires a complex derivation of structure building and erasure to achieve primary accent assignment. Furthermore, and more critically, this analysis suffers from the same shortfall as Stowell's analysis: the binary bounded feet do not continue after the tonic syllable, and therefore even penults are indistinguishable from odd penults. Additionally, the final representation cannot account for multiple accents in a word. The final representation in $(d)$ of figure 4 (right column) 


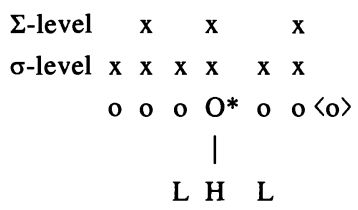

FIG. 5

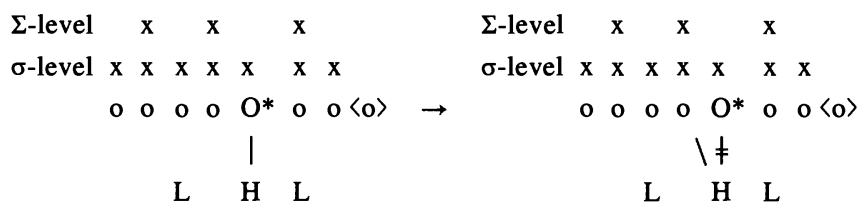

FIG. 6

would assign an additional accent on both the second and the fourth syllable of this hypothetical word, while the correct result would assign accents only to the second and sixth syllables, not the fourth, since it is neither closed nor followed by a closed syllable.

Both previous metrical analyses of Seneca accent share the same fatal flaw; they cannot distinguish even- and odd-numbered penults. This led Prince (1983) to take a different approach to Seneca accent assignment, namely, by combining metrical structure with a tonal level.

In Prince's (1983) framework, there are no metrical constituents or feet. Instead, he uses grid marks which strictly alternate between stressed and unstressed syllables, either peak first $\left(*^{*} . * . *\right.$.) or trough first $\left(.^{*} .^{*} * *\right)$. In Seneca, the (w s) iambic alternation is modeled by a trough-peak alternation in the metrical grid, as shown in figure 5 on the foot $(\Sigma)$ level. On a separate tonal tier, he proposes that Seneca has an LHL tonal melody. The high tone is specified to associate to the last medial closed syllable, while the two low tones spread left- and rightward. Primary accent is assigned to the intersection of the two distinct tiers of representation, thus aligning them. The schema in figure 5 illustrates how this procedure works for instances where the last medial closed syllable is even. On the syllable $(\sigma)$ level of representation, each syllable receives a beat. On the $\Sigma$ level, the perfect grid assigns every other syllable a beat. (Open syllables are represented with $o$ and closed syllables are represented by $O$.)

When the rightmost closed syllable is odd, Prince makes use of a process, Backward $\mathrm{H}$-spread, which spreads the high tone associated with the 


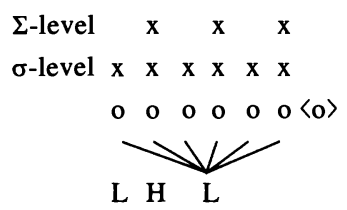

FIG. 7

closed odd syllable backward onto the preceding even-numbered syllable. In this way, the two levels of representation align even when the high tone does not initially associate to a syllable with a beat on the $\Sigma$ level of representation. A schema for a word with a closed odd-numbered syllable is provided in figure 6 .

When a word has no medial closed syllable, the high tone has no syllable with which to associate. Instead, the low tone spreads over the entire word, resulting in words without any accented syllable, as in figure 7.

Prince's analysis rests on the justifiability of the Backward H-spread rule. His argument is based on the existence of a related phenomenon in Onondaga. In Onondaga, stress and pitch have separated and they generally occur on separate syllables. In the majority of words, penultimate syllables are assigned stress, i.e., they are louder and higher in pitch than unstressed syllables, while pretonic syllables receive a high tone which has an $\mathrm{f}_{0}$ that is even higher than that of the tonic syllable (Chafe 1977, Woodbury 1977, Gibson 1992, and Michelson 1988). Chafe (1977) additionally describes some words for which the pitch on the pretonic syllable is equally as high as the pitch of the tonic syllable-not higher, as is normally the case. Chafe claims that these words have maintained the original PNI penultimate accent plus a process of "pretonic pitch raising," from which Prince motivates his Backward H-spread rule for Seneca. However, an alternative characterization of the Onondaga facts is provided by Woodbury (1977) (see also Gibson 1992 and Michelson 1988). Woodbury's description does not support the existence of a set of words which exhibit pre-tonic pitch raising. Thus, whether such a phenomenon is actually attested in Onondaga is still an empirical issue. However, although tone "flop" rules such as Prince's Backward $\mathrm{H}$-spread rule are fairly common cross-linguistically, the apparent absence of a pre-tonic pitch-raising phenomenon in Onondaga renders the Backward $\mathrm{H}$-spread rule ad hoc for Seneca.

Furthermore, some Iroquoian languages provide evidence for a Rightward $\mathrm{H}$-spread rule. Again, evidence comes from Oneida. As described in 3.2.3 above, in Oneida, accent is usually assigned to the penultimate syllable. However, when the penult is open, it is lengthened and the accent shifts to the final syllable (Michelson 1988). 


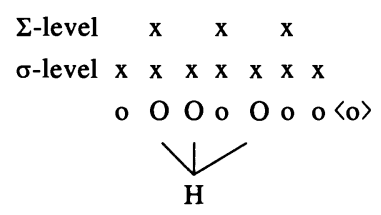

FIG. 8

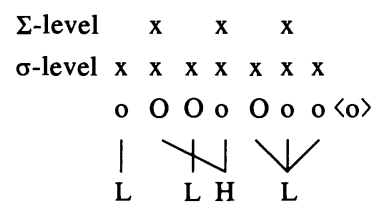

FIG. 9

In addition to the lack of historical support for Prince's Backward Hspread rule, his analysis faces a second problem from the recent description of multiple accents. If every accentable syllable in a word is assigned a high tone, then it is clear that the tonal melody LHL cannot be correct. Furthermore, since there is no way to predict how many accentable syllables a word will have, no lexically specified tonal melody can adequately account for the accent pattern in Seneca. One possible way to salvage the tonal approach is to propose a tonal melody that consists only of a single $\mathrm{H}$ tone that docks to every closed syllable in a word. Syllables without an $\mathrm{H}$ tone are assigned a default low tone. However, this proposal is itself problematic. First, it requires that the $\mathrm{H}$ tone spread over the whole word, skipping open syllables and docking only at closed syllables. However, once the open syllables are assigned default $\mathrm{L}$ tones, the representation will violate the tone association rules, namely, that association lines must not cross. Following Pulleyblank (1986) and others, I assume that default tones are represented on the tonal tier at the final stage of a derivation. Thus, even if we assume multiple individual default tones, the final representation will still include crossed association lines, something which is universally disallowed. An example of what the final representation for a word with multiple accents would look like under Prince's analysis is presented in figures 8 and 9.

In figure 8, the $\mathrm{H}$ tone spreads over the whole word, skipping open syllables and docking at all the closed syllables. In figure 9, Backward $\mathrm{H}$-spread applies where necessary, shifting one $\mathrm{H}$ tone leftward and deleting another. Default low tones are then assigned, resulting in the crossed association lines. To avoid crossing association lines, the tonal analysis would need to be able to generate as many individual high tones as are needed for each 
individual word. How such a process of $\mathrm{H}$ tone duplication could be incorporated into Prince's analysis is unclear.

To summarize, the two purely metrical analyses which have assumed iambs fall short of the empirical facts because they cannot distinguish even and odd syllables for purposes of EPL. Prince's hybrid analysis can distinguish even and odd penults, but his analysis has difficulty accounting for multiple accents. Furthermore, I also argued that the Backwards $\mathrm{H}$-spread rule, which is crucial to Prince's analysis, is not supported by the facts of Onondaga and a competing tone spreading rule from Oneida provides evidence of tone spreading in the opposite direction. In contrast, while the trochaic analysis presented in this paper requires a typologically unusual mechanism, namely, initial extrametricality, it can account for the full range of accent and accent-related phenomena. Futhermore, leftward tone spreading is independently motivated by the metrical structure.

4. Conclusion. I have attempted to provide an innovative analysis of Seneca accent assignment and related phenomena. The present analysis accounts for both single and multiple accents and accentless words, and it is compatible with other prosodic phenomena in the language, particularly EPL. I have taken the seemingly complicated accent pattern of Seneca and made it more natural by reinterpreting Seneca metrical structure as trochaic. The reinterpretation facilitated the analysis of accent assignment by placing the conditioning environment and the accent realization into the same foot. Closed odd-numbered syllables reject accent because they are in the weak branch of a foot. Accent moves leftward, an unexpected direction given the rightward preference generally exhibited by Iroquoian languages, because accent must respect the foot boundary.

By observing that all iambic analyses suffer the same problem of crossing the foot boundary, I was able to approach Seneca from a completely new direction. This approach gave rise to a simple analysis of a previously intractable phenomenon. The present analysis needed only to propose that Seneca has an initial extrametrical syllable to account for the facts of the language, a proposal that is supported by processes and intonation patterns from other Iroquoian languages. Furthermore, an examination of the typological characteristics of Seneca supported the reclassification of the foot type used by the metrical system.

In conclusion, let me return briefly to the question of whether the high pitch on accented syllables is phonological or phonetic. I have argued in this paper that accent assignment in Seneca relies only on metrical structure. Thus, for the current analysis, it is assumed that the high pitch on accented syllables is the phonetic realization of phonologically determined accent. Prince (1993) and, subsequently, Hayes (1995) argue for an analysis which additionally includes a tonal level of representation that interacts 
with the metrical structure. Thus, high pitch is an underlying characteristic that forms part of the system that assigns accent to syllables.

There are several reasons to prefer a partly tonal analysis over a purely metrical one. First, tone flop rules such as the Backward H-spread rule proposed by Prince are typologically more common than initial extrametricality, which was required for the trochaic analysis. Furthermore, other Iroquoian languages show clear evidence for a separation of the metrical and tonal levels of representation-Onondaga has a clear separation between stress and tone (Chafe 1977, Woodbury 1977, and Michelson 1988). Finally, by adopting a partly tonal analysis, one avoids the complications raised by Seneca's violation of culminativity.

However, as argued above, the Backwards $\mathrm{H}$-spread rule is not supported by other Iroquoian languages and the direction of the spreading is not expected, given the general preference in Iroquoian languages to have accent occur near the right edge of a word. Furthermore, related languages did provide some support for attributing a special status to initial syllables, e.g., the data presented from Cayuga and Onondaga. Thus I would argue that there is more support from related languages for initial extrametricality than for the Backward H-spread rule. Finally, the tonal analysis simply does not account for the same range of data as the trochaic analysis; it cannot adequately account for multiple accents. Thus, despite the potential benefits of assuming that the high tone is phonologically represented, the data suggest that the high tone is the phonetic realization of metrically determined accent.

\section{REFERENCES}

Bell, Alan. 1977. Accent placement and perception of prominence in rhythmic structures. Studies in Stress and Accent, ed. Larry M. Hyman, pp. 1-13. Los Angeles: Department of Linguistics, University of Southern California.

BeCKMAN, Mary. 1986. Stress and Non-Stress Accent. Dordrecht: Foris.

Chafe, Wallace. 1959. Internal reconstruction in Seneca. Language 35:477-95. 1967. Seneca Morphology and Dictionary. Smithsonian Contributions to Anthropology 4. Washington, D.C.: Smithsonian Institution Press. Press. 1970. A Semantically Based Sketch of Onondaga. Bloomington: Indiana University

1977. Accent and related phenomena in the Five Nations Iroquois languages. Studies in Stress and Accent, ed. Larry M. Hyman, pp. 169-81. Los Angeles: Department of Linguistics, University of Southern California.

1996. Sketch of Seneca: an Iroquoian language. Handbook of American Indian Linguistics, vol. 17, ed. Ives Goddard, pp. 551-79. Washington, D.C.: Smithsonian Institution. . 1998. Morphology and discourse determinants of pitch in Seneca. Paper presented at the annual meeting of the Linguistic Society of America, Chicago.

Chafe, Wallace, and Michael Foster. 1981. Prehistoric divergences and recontacts between Cayuga, Seneca, and the other Northern Iroquoian languages. IJAL 47:121-42. 
DYCK, CARRIE. 1997. Cayuga accent: a synchronic analysis. Canadian Journal of Linguistics 42:285-322.

FOSTER, MICHAEL. 1982. Alternation of weak and strong syllables in Cayuga words. IJAL 48:59-72.

Gibson, JoHn. 1992. Concerning the League: The Iroquois League Tradition as Dictated in Onondaga. Algonquian and Iroquoian Linguistics Memoir 9.

Hale, Ken, ANd Josie White Eagle. 1980. A preliminary metrical account of Winnebago accent. IJAL 46:117-32.

Halle, Morris, and Jean-Roger Vergnaud. 1987. An Essay on Stress. Cambridge, Mass.: The M.I.T. Press.

HANDEl, StePhen. 1974. Perceiving melodic and rhythmic auditory patterns. Journal of Experimental Psychology 103:922-33.

HAYes, Bruce. 1981. A metrical theory of stress rules. Ph.D. dissertation, Massachusetts Institute of Technology. [Revised version distributed by Indiana University Linguistics Club, Bloomington, and published by Garland Press, 1985.] 306. 1989. Compensatory lengthening in moraic phonology. Linguistic Inquiry 20:253-

1995. Metrical Stress Theory. Chicago: University of Chicago Press.

HEIBERG, ANDREA. 1995. A non-derivational approach to Winnebago stress. Proceedings of the Twenty-first Annual Meeting of the Berkeley Linguistics Society, University of California, Berkeley.

HyMAN, LARRY 1985. A Theory of Phonological Weight. Dordrecht: Foris.

KAGER, RENÉ. 1989. A Metrical Theory of Stress and Destressing in English and Dutch. Dordrecht: Foris.

1993. An alternative to the Iambic-Trochaic Law. Natural Language and Linguistic Theory 11:381-432.

Liberman, Mark, and Alan Prince. 1977. On stress and linguistic rhythm. Linguistic Inquiry 8:249-336.

McCarthy, John, and Alan Prince. 1986. Prosodic morphology. Ms., Department of Linguistics, University of Massachusetts, Amherst, and Program in Linguistics, Brandeis University.

Melinger, Alissa. 1997. Syllabification, foot structure and accent in Seneca. Ms., University at Buffalo, State University of New York.

Michelson, Karin. 1988. A Comparative Study of Lake-Iroquoian Accent. Boston: Kluwer.

Mithun, Marianne. 1979. Iroquoian. The Languages of Native America, ed. Lyle Campbell and Marianne Mithun, pp. 133-212. Austin: University of Texas Press.

Prince, Alan. 1980. A metrical theory for Estonian quantity. Linguistic Inquiry 11:511-62. 1983. Relating to the grid. Linguistic Inquiry 14:19-100.

1990. Quantitative consequences of rhythmic organization. Proceedings of the Twenty-sixth Annual Meeting of the Chicago Linguistic Society, pp. 355-98.

Pulleyblank, Douglas. 1986. Tone in Lexical Phonology. Dordrecht: Kluwer.

STOWELl, TIM. 1979. Stress systems of the world, unite! Papers on Syllable Structure, Metrical Structure and Harmony Processes, M.I.T. Working Papers in Linguistics I, ed. K. Safir. Boston: Department of Linguistics and Philosophy, Massachusetts Institute of Technology.

Woodbury, HaNnI. 1977. Sentence-final accent in Onondaga. Paper presented at the Conference on Iroquoian Research, Rensselaerville, N.Y. 1981. The loss of a phoneme. IJAL 47:103-20.

WOODROw, HeRBERT. 1909. A quantitative study of rhythm. Archives of Psychology 14:1-66. 1911. The role of pitch in rhythm. Psychological Review 18:54-77. 